\title{
CHANGE IN THE URBAN SPATIAL STRUCTURE OF THE GREATER CAIRO METROPOLITAN AREA, EGYPT
}

\author{
Ahmed Abdelhalim M. Hassan \\ Institute of Landscape Ecology, Muenster University, Muenster, Germany, \\ e-mail ahmedahalim@uni-muenster.de
}

Volume XXXVIII, ISSN: 1628-1777

KEY WORDS: Greater Cairo; pixel-based and object-based classifications; land use/ land cover (LU/LC); change detection analysis,

\begin{abstract}
:
Since the 1980s, rapid population growth and urbanization have become issues in big cities like Greater Cairo (GC). As a consequence of explosive growth, the living conditions of Cairo Metropolis deteriorate. Development trends of the last twenty years have increased general wealth and modernization, this sets out how GC megacity is creating an increased demand for land combined with environmental degradation.

Planning a sustainable development of mega cities requires understanding of physical change of the main environmental drivers. However, this talk will be concerned with monitoring and analysis of dynamic environment changes to capture and refine the urban patterns in Greater Cairo Metropolis on the basis of pixel-based and object-based classifications. Satellite images (TM, ETM+, \& Spot) of different dates and resolutions, and ground truth data collected from available maps, field observation, and personal experience were used to execute the image segmentation analysis to reveal urban patterns and expansions.

By using Erdas Imagine, and eCognition Developer software, land use / land cover image classifications were constructed, which detect regimes and trends in land changes.

Two main types of urban patterns could be detected (passing from centre to periphery). The first one is informal and the second one is formal building. The informal type mainly comprises slums and urban encroachment on arable land. The formal one mostly consists of new cities and legal houses. Moreover, a rate of land cover changes in Greater Cairo during the last three decades could be described as a rapid progression.

In contrast, the combination between field observations and classification analyses showed that the high urban densities based on classification of satellite images does not reflect the real densities of population in urban areas in Greater Cairo.
\end{abstract}

\section{INTRODUCTION}

Nowadays, three out of six human beings live in cities, two of whom live in developing citites. These figures illustrate the scale of the challenge represented by urban development in today's world and the growing pressure it currently puts on all levels of the city.

Urban planners and administrative bodies require reliable information to assess the consequences of urbanization, to ensure a sustainable functioning of cities and to minimize negative impacts of rapid urbanization. Urban expansion in the developing world often takes place in an unplanned manner and administration is unable to keep track of growth-related processes (Griffiths et al., 2009).

Remote sensing based information is one of the most important resources to support urban planning and administration in megacities (Maktav et al., 2005). Remotely-sensed information is hence of particular relevance in the worlds developing countries because it provides fundamental information on growth-related processes and their effect on the urban environment that are not available from other sources (Miller \& Small, 2003).

Although satellite imagery provides a synoptic view of the urban mosaic, remote-sensing data can be an important complement to limited in situ measurements in urban areas (Kwarteng \& Small 2010).

Pixel-based approaches use conventional statistical techniques, such as supervised and unsupervised classification. In supervised classification, the image analyzed "supervised" the pixel categorization process by specifying, to the computer algorithm, numerical descriptions of the various land cover- types present in a scene. This approach has shown good accuracy for images acquired by course resolution sensors, while in the case of very high resolution (VHR) images it was considered that the spectral mutability increases within a particular class, making the extraction of thematic information more difficult (Foody, 2002). Various new techniques take into account, besides the spectral data, also the texture features of the image as an additional layer in the classification process (Puissant et al., 2005). An improved accuracy, especially for urban land-use/ land-cover classifications, has been proposed by the object-based classifications. Hence, object-based analysis facilitates work with meaningful image objects and their mutual relationships (Matinfar et al., 2007).

This paper describes and discusses different remote sensing (RS) techniques to monitor and analyse dynamic expansion and urbanization in Greater Cairo. Since pixel-based analysis in complexly structured land-use and land-cover (LU/LC) areas is limited because the semantic information necessary to interpret an image is usually not represented in single pixels, both pixeland-object-based approaches were applied and compared. This involves a certain trade-off between the richness of detail of VHR remote sensing imagery such as Spot Image and the generalizing nature of moderate to high resolution sensors such as the $30 \mathrm{~m}$ spatial resolution of Landsat TM and ETM+ used in this study.

\section{STUDY AREA}

The selected area of study is the metropolitan area of Greater Cairo and its surroundings, which is known as the capital of Egypt and one of the fastest growing megacities worldwide (Figure 1). The area covers about $600 \mathrm{~km}^{2}$, encompassing major 
parts of the governorates of Cairo, Giza, Six October, and Helwan. The Nile forms the administrative division between these governorates, with Cairo and Helwan on the east bank of the river and, Giza and Six October on the west bank. The area includes a variety of land uses associated with a complex mix of land cover, such as a central business district (CBD), urban/ suburban residential areas and some rural areas (e.g. cultivated areas and soil). This area has encountered rapid urban development and population growth in the last 20 years.

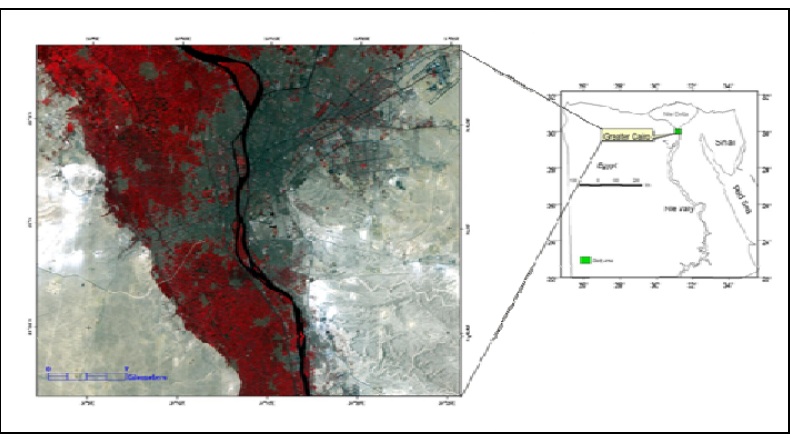

Figure 1. Location of the study area

\section{MATERIALS AND METHODS}

This study is based on three Landsat TM \& ETM images dates (path 176, row 39): 1984, 1990, and 2006 (the image of 1984 is considered as the reference year for the other images). Moreover, a multi-spectral spot mosaic acquired in 2006 has been chosen. These data were processed using ground control points and have a geometric error within 30,15 , and $5 \mathrm{~m}$ respectively.

\subsection{Image processing}

If A series of processing operations was performed on these images. The images were georeferenced using UTM map projection for zone 36 and WGS 84 datum. The images were resampled to $30 \mathrm{~m}$ for bands $1,2,3,4,5,7$, to $15 \mathrm{~m}$ for panchromatic and to $60 \mathrm{~m}$ for thermal bands using the nearest neighbor technique. In order to produce a test area, false color composites from ETM+ bands 7, 5 and 3 were used, while all of the six bands (ETM+ bands 1, 2, 3, 4, 5 and7) were used for pixel-based classification. Additionally, a subset of spot images mosaic of the study area was compiled, which was used for soft method of object-based classification.

\subsection{Pixel-based classification}

Supervised classification was performed using TM and ETM+ bands. In supervised classification, the basic steps followed were (1) select training samples which are representative and typical for that information class; (2) perform classification after specifying the training samples set and classification algorithms of Erdas Imagine software. Training samples were selected according to ground truth. These homogenous areas were identified in the image to form the training samples for all of the information classes. The selected algorithm for performing the supervised classification was the minimumdistance classification. In this algorithm first the mean spectral value in each band for each class is determined. These values comprise the mean vector for each class. This distance threshold could vary for each class depending on the expected degree of compactness of that class. Compactness might be estimated from the standard deviation for each feature of the pixels making up the training sample for a given class.

In vegetation studies the ratio (known as vegetation indices) is used to enhance the spectral differences between strong reflectance of vegetation in the near-infrared part of spectrum and chlorophyll-absorption band (red part) of the spectrum (Singh, 1989). NDVI is one of typical vegetation indices proposed by (Rouse et al. 1974). The NDVI derived from the ratio of band 3 and band 4 in Landsat TM and ETM images data was applied for monitoring vegetation changes in the study area within the years of 1984, 1990 and 2006.

\subsection{Object-based classification}

Object segmentation module was used for object-oriented analysis and classification. Segmentation is the main process in the classification module in eCognition Developer software and its aim is to create meaningful objects. This means that an image object should ideally represent the pattern of each object in question. This pattern combined with further derivative color and texture properties can be used to initially classify the image by classifying the generated image objects.

Thereby the classes are organized within a class hierarchy. With respect to the multi-scale behavior of the objects to detect a number of small objects can be aggregated to form larger objects constructing a semantic hierarchy (Matinfar et al. 2007). In performing the segmentation of the Spot image, four spectral bands $(5 \mathrm{~m}$ resolution $1,2,3,4)$ took in the segmentation process with full weight.

\section{RESULTS}

\subsection{Change detection}

The Six land use / land cover (LU/LC) classes were recognized based on change detection in the first level (pixel-based classification) to be distributed in the study area: Urban areas (U), Cultivated Land (CL), Cultivated to Urban (CU), Desert (D), Bare Soil (BS), and Water Bodies

(WB) (Figure. 2) and (Table. 1).

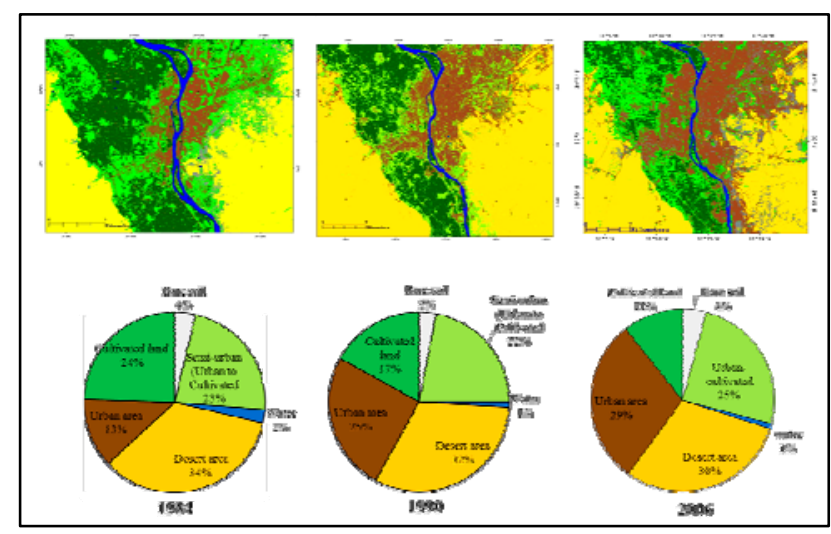

Figure 2. Change detection in study area

Table 1: Percentage of LU / LC classes in the study area

\begin{tabular}{|l|l|l|l|}
\hline $\begin{array}{l}\text { LU / LC (Land } \\
\text { use/cover) }\end{array}$ & $1984 \%$ & $1990 \%$ & $2006 \%$ \\
\hline U (Urban areas) & 12 & 25 & 29 \\
\hline $\begin{array}{l}\text { CL (Cultivated } \\
\text { land) }\end{array}$ & 24 & 17 & 11 \\
\hline
\end{tabular}




\begin{tabular}{|l|l|l|l|}
\hline $\begin{array}{l}\text { CU (Cultivated } \\
\text { to urban) }\end{array}$ & 23 & 22 & 25 \\
\hline D (Desert area) & 35 & 32 & 30 \\
\hline BS (Bare soil) & 4 & 3 & 4 \\
\hline $\begin{array}{l}\text { WB (Water } \\
\text { Bodies) }\end{array}$ & 2 & 1 & 1 \\
\hline
\end{tabular}

The following conclusions are short comings that limit the accuracy of classification based multi-resolution/ multitemporal change detection by using the pixel-based classification techniques:

- $\quad$ Limited spectral separation of classes.

- The statistical independence assumption pixel-based classifications involve the $\mathrm{DN}$ values individually without considering the neighbourhood pixels (Castelli et al., 1999).

- Land cover maps derived from classification of images usually contain some sort of errors due to several factors that range from classification techniques to methods of satellite data capture. Hence, evaluation of classification results is an important process in the classification procedure.

- The intrinsic limitation of classifiers - comparison of image data in a change detection procedure requires more research that would involve new approaches of multi-scale analysis.

\subsection{The Normalized Difference Vegetation Index (NDVI)}

The results of the NDVI which computed for each of the three time series images (1984, 1990 and 2006) were processed by using the change detection modeller of the image processing Imagine software. The change detection results are presented in (Figure. 3). The results showed that vegetation cover in the entire study area was changed by anthropogenic urbanization. Since, the change in NDVI shows darker in encroachment areas between years 1984-1990 and more darker areas between years 1984-2006.

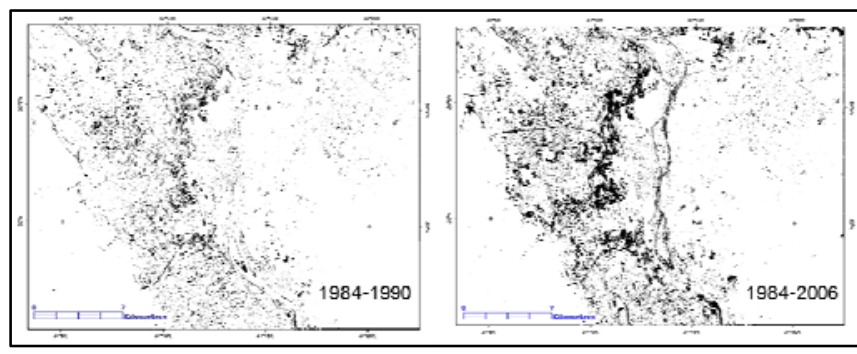

Figure. 3. The degree of changes of cultivated land based on NDVI indices

Note: The dark area represents a high degree of change

\subsection{Image segmentation}

Two levels for automatic identification of the urban classes on the multi-spectral spot mosaic were applied by image segmentation module in Developer software for the objectoriented-classification:

1) Formal-informal urbanization level (Fig. 4)

The formal urbanization represented here by the legal house dominated mainly by the cores of Cairo and Giza cites, and new urbanization areas established in the hinterland.

2) Informal urbanization segmentations level (Fig. 5). While, the informal urbanization described here by the illegal slums built-up in the plateaus around the old Cairo city and urban sprawl over the cultivated land in all over the Greater Cairo.

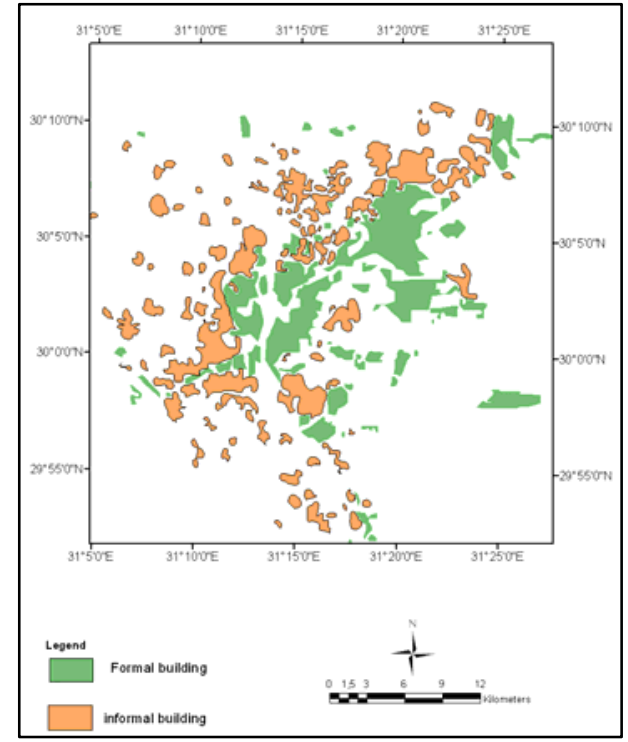

Figure 4. The distribution of formal (green) and informal urbanization (brown) in the study area

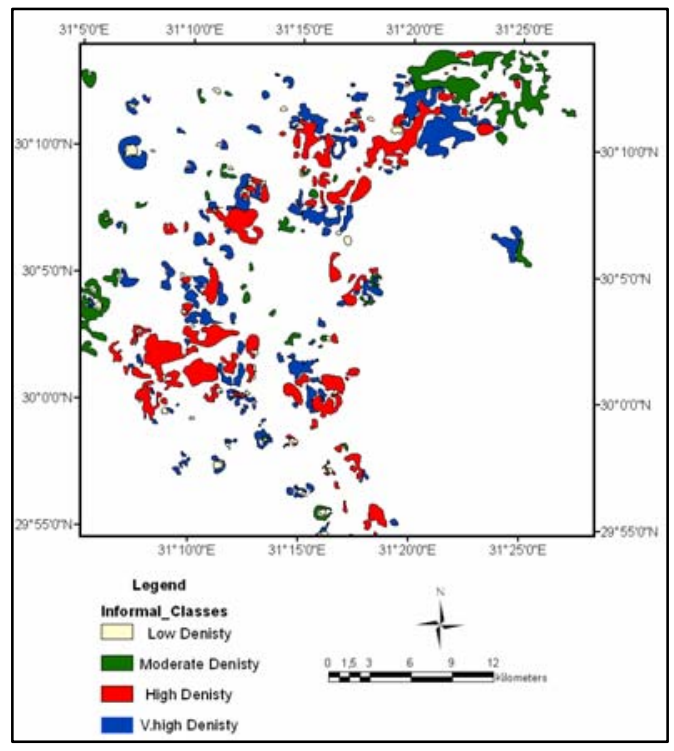

Figure 5. The classes of informal urbanization in the study area according to the textural density and shape

Objects are described by their specific spectral information, shape, and texture. The brightness relationship of adjacent image objects was worked out explicitly. For that purpose, the relationships between objects were established. Based on the objects and the class descriptions, a fuzzy soft-classification was implemented. Whatever, shape characteristics such as size and density of objects, and neighbourhoods characteristics for topological and brightness relationships analyses, were used.

The first-level classification of pixel-based method was integrated into the object-based segmentation, which represented the second level of classification. Objects in the second-level classification were concerned to describe the formal and informal urbanization. A further classification process could be carried out to generate the third level of 
segmentation. This level was distinguished by four child classes (LUC1, LUC2, LUC3, and LUC4). These child classes were described as low, moderate, high, very high dense urbanization respectively.

\section{DISCUSSION}

It can be assumed that the proportion of built-up surface is closely related to population density (Mesev, 1998). In Greater Cairo (GC) in years 1986-1999 (Zhi-Yong et al. 2005) concluded that by integrated remote sensing and GIS technologies, the relation between built-up surface and population were quantified. While most increases in built-up surface were found in the outer margin of the Greater Cairo area, population per unit built-up area increased most significantly in the suburbs and to the south of the city.

Controversially, in this study, the field observations in many urban areas in suburbs and to the south of the $\mathrm{GC}$ region dominated by high density of informal buildings (Figure 6) were showed a high percentage of empty to sub-empty houses. Thus has a strong criterion to the changes in built-up surface in such areas after year 1999. Therefore, the correlation between the classified urban areas in Greater Cairo by using image segmentation and analysis and population density has weak significance.

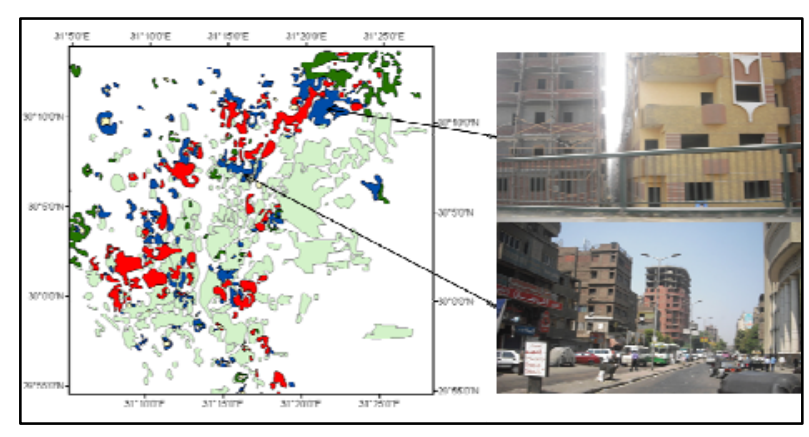

Figure 6. Field observations are showing empty buildings in high density classified areas

\section{RECOMMENDATIONS AND CONCLUSIONS}

It can be concluded that the pixel-based classification, which was applied on Landsat TM and ETM+ time-series images, is useful for monitoring the dynamic increasing of megacities and large areas. While the object-oriented classification deals more sufficiently with the urban environment including formal and informal buildings. The high level of object-oriented segmentation, which was applied on the very high resolution images, is recommended for sub-object accuracy classification. Furthermore, analysis of census by using such classifications could be inaccurate. For example, in Greater Cairo the high densities of houses are not reflecting real population densities, due to the many houses are empty or partially empty.

Moreover, a rate of land cover changes in Greater Cairo during the last three decades would be described as a rapid progression.

\section{REFERENCES}

Castelli V., Elvidge C. D., Li C. S. and Turek J. J.: Classification-based change detection Theory and applications to the NALC dataset. In remote sensing change detection: Environmental monitoring methods and applications, edited by R.S. Lunetta and C. D. Elvidge.London, UK: Taylor \& Francis, 53-73, 1999.

Foody G. M.: Status of land cover classification accuracy assessment. Remote Sensing of Environment 80, pp. 185-201, 2002.

Griffiths P., Hostert P., Gruebner, O., and Linden S.: Mapping megacity growth with multi-sensor data. Remote Sensing of Environment 114, 426-439, 2009.

Kwarteng A. and Small E.: Remote Sensing of Urban and Suburban Areas, Remote Sensing and Digital Image Processing, Volume 10, Part 2, pp. 267-287, 2010.

Liyin Shen, Rowson K. H. Lee, and Zhihui Zhang: Application of BOT System for Infrastructure Projects in China, Issue 4 / J. Constr. Eng. Manage. pp. 122-319. 1996.

Maktav D., Erbek, F. S., and Jurgens, C.: Remote sensing of urban areas. International Journal of Remote Sensing, 26, 655-659, 2005.

Matinfar H.R., Sarmadian F., Alavi Panah S.K., and Heck R.J.: Comparisons of Object-Oriented and Pixel-Based Classification of Land Use/Land Cover Types Based on Lansadsat7, Etm+ Spectral Bands (Case Study: Arid Region of Iran)", American-Eurasian J. Agric. \& Environ. Sci., vol 2 (4), p.p. 448-456, 2007.

Mesev, V.: The use of census data in urban image classification. Photogrammetric Engineering and Remote Sensing, 64(5), pp.431-438, 1998.

Miller R. B., and Small, C.: Cities from space: Potential applications of remote sensing in urban environmental research and policy. Environmental Science \& Policy, 6, pp. 129-137, 2003.

Netzband, William M., Stefanov, L., and Charles Redman, C. (eds.): Applied remote Sensing for Urban Planning, Governance and Sustainability. Springer: Reference Book, Heidelberg 2009.

Puissant, A., Hirsch, J. and C. Weber.: The utility of texture analysis to improve per-pixel classifications for high to very high spatial resolution imagery. International Journal of Remote Sensing 26(4): 733-745, 2005.

Rashed T., J.R. Weeks, M.S. Gadalla and A.G. Hill: Revealing the anatomy of cities through spectral mixture analysis of multispectral satellite imagery: A case study of the Greater Cairo Region, Egypt, Geocarto International 16, pp. 5-15, 2001.

Ridd M.: Exploring a V-I-S (Vegetation-Impervious SurfaceSoil) Model for Urban Ecosystem Analysis through Remote Sensing: Comparative Anatomy of Cities. International Journal of Remote Sensing 16 (12): 2165-2185, 1995.

Rouse, J. W., R. H. Haas, J. A. Schell, D. W. Deering, and J. C. Harlan.: Monitoring the Vernal Advancements and Retrogradation (Greenwave Effect) of Nature Vegetation, NASA/GSFC Final Report. NASA, Greenbelt. MD, USA, 1974.

Singh, A. Review Article: Digital change detection techniques using remotely-sensed data.Int. J. Remote Sensing, 10(6), 989-1003, 1989.

Zhi-Yong Y., Dona J. Stewart, Stevan Bullard, Jared T. MacLachlan: Change in urban built surface and population distribution patterns during 1986-1999: a case study of Cairo, Egypt. Computers, Environment and Urban Systems, 29, pp. 595-616, 2005. 